\title{
Da Ética Policial: um Pressuposto no Uso DA ForÇa EM PORTUgal
}

\author{
Bruno Miguel fena Torres \\ Centro de InvestigaÇão do Instituto Superior de Ci- \\ Ências Policiais (ICPOL) e Segurança Interna (ISCPSI) \\ DE LISBOA
}

\begin{abstract}
RESUMO
Os Direitos Humanos e a dignidade da pessoa humana são a premissa principal numa atuação policial. A força legítima empregada pela polícia, de modo a prover segurança aos demais cidadãos é um símbolo de soberania e a razão da existência de um Estado democrático.

A atuação das instituições securitárias poderá levantar uma dúvida ética, já que esta acaba por ser a garantia e a legitimação da ação das forças de segurança, torna-se necessário aferir qual o limite do sacrifício da ética na atividade policial, através da restrição de certos direitos, liberdades e garantias dos cidadãos. Poderá uma intervenção policial violenta proteger a ética do homem? A própria violência policial não se deve constituir como uma forma de violência destrutiva; deve sim, seguir determinados parâmetros éticos. Em tal contexto, intenta-se investigar qual a legitimidade do uso da força em ação policial, indissociável da perspectiva normativo-legal e dos demais princípios norteadores da atividade policial, em especial dos referentes ao recurso do uso da força policial.
\end{abstract}

Palavras-Chave: Direitos humanos. Dignidade humana. Ética e moral. Ética policial. Força policial.

\section{INTRODUÇÃO}

A defesa da dignidade humana tornou-se relevante principalmente após a Segunda Guerra Mundial, com a Carta das Nações Unidas de 1945 e a Declaração Universal de Direitos Humanos de 1948. A Declaração de Direitos Humanos e do Cidadão celebrada pela Assembleia Constituinte Francesa de 1789 já havia sido um escrito importante para a história dos direitos humanos. O documento de 1948 
coloca em evidência os pilares da dignidade humana ao mencionar que "todas as pessoas nascem livres e iguais em dignidade e direitos. São dotadas de razão e de percepção e devem agir em relação umas às outras com espírito de fraternidade" . A dignidade começava a ser percepcionada como algo inato ao ser humano, algo inviolável, onde o contexto societal no qual o cidadão se insere é tão somente onde a dignidade se realiza.

O marco da 2. ${ }^{a}$ Grande Guerra está associado igualmente ao aparecimento de outro conceito, que a par da dignidade ganha relevo - a ética. Um conceito normalizador por um conjunto de princípios disciplinadores da ação humana e motivadores para a existência de uma sociedade mais humana. A sociedade evolui de forma direta com o progresso ético na proteção da dignidade da pessoa humana, cuja consciência ética dos homens e das nações se vê refletida no artigo 1. ${ }^{\circ}$ da Declaração Universal de Direitos como um alicerce de todos os direitos, liberdades e garantias.

A consciencialização do ser humano para a necessidade de uma construção permanente de uma sociedade onde todos consigam viver torna-se imperativa. Jamais um indivíduo deve ser observado como uma ameaça à liberdade do outro; liberdade esta que deve começar com a entrada desse outro no mundo de relações interpessoais, respeitando-se as diferenças de cada um. Consciente de que nem sempre o desejável é alcançável, recai sobre o Estado social o monopólio da satisfação das necessidades coletivas (OTERO, 1995), enquanto o único detentor da violência legítima (MATIAS, 1978).

À polícia, um instrumento do Estado, é-lhe exigida uma atuação legítima, pois embora detenha o predicado legal do recurso à violência, cada vez mais a questão da coercibilidade policial é questionada e mediatizada socialmente.

O uso da força legítima e da violência são fenômenos intimamente relacionados, delimitados por uma linha muito ténue. Importa perceber que "o poder policial de usar a força não é de exibição permanente, é antes uma potencialidade a que os corpos policiais podem recorrer em determinadas situações" (ALVES, 216, p. 7). A arbitrariedade do uso

1 Artigo $1^{\circ}$ da Declaração Universal de Direitos Humanos. 
da força é uma questão complexa e um assunto gerador de controvérsia, cuja problemática assenta no estudo da ética da atuação policial.

É objetivo deste artigo debruçar-se sobre a questão do fenômeno do uso da força policial, sob uma base ético-deontológica e legitimada pelos limites legais normativos e os princípios norteadores da ação policial. Para tal, definiram-se os seguintes objetivos: perceber a origem dos conceitos de direitos humanos e de dignidade associados à própria ética - um elemento orientador da atuação policial; e definir a legitimidade da polícia no uso da força em ação policial.

Metodologicamente, para investigação respaldada do acima proposto, articular-se-á uma concepção teórica qualitativa, com recurso a diversas fontes de informação. Este artigo terá o auxílio da realização de uma pesquisa bibliográfica de livros, de artigos científicos, de jurisprudência, de pesquisa de fontes digitais, de uma análise documental diacrônica e sincrônica com incidência em legislações e leis orgânicas das polícias, com o objetivo de identificar o problema.

\section{Os Direitos Humanos e a Dignidade}

O conceito dignidade foi sofrendo alterações nos tempos e alvo de evolução. Se inicialmente era entendido e relacionado com a honra, onde um homem digno era aquele que tinha alguma fama pelo seu bom nome; nos dias de hoje, acaba por ser a recompensa coletiva duma herança autêntica de civilização.

Se inicialmente lhe era atribuída uma conotação social, entendido como a reputação ou o bom nome, chegou-se a uma interpretação antropológica. Após uma época, nomeadamente nos séculos de XV a XVII, em que o conceito não foi muito abordado, Kant procurou explorá-lo sob o ponto de vista ético de dignidade da pessoa humana. O filósofo alemão defendia que ou se tem preço ou se é digno e que o ser humano não é algo que se substitui por algo equivalente, pelo que tem a qualidade de ser digno, é um ser de valor absoluto. O próprio bem coletivo jamais poderá exceder aquilo que corresponde à dignidade mínima de cada um. Para Kant "o homem [e, de uma maneira geral, todo o ser racional] existe como fim em si mesmo, e não apenas 
como meio para o uso arbitrário desta ou daquela vontade" (BARRETO, 2013, p. 56).

Na senda de Sousa (2011, p. 303) a "dignidade humana é oferecida pela Natureza identicamente a todos os seres humanos, insuscetível de ser perdida por qualquer homem, em qualquer circunstância”. A dignidade é intrínseca ao ser humano, algo impossível de se perder, contrariamente a determinados direitos, pelo que apesar do princípio da dignidade da pessoa humana ser o culminar da evolução da sociedade, a pessoa humana sempre foi digna, faz parte da sua natureza. A este respeito Sarlet (2001, p. 72) refere que "mesmo aquele que já perdeu a consciência da própria dignidade merece tê-la considerada e respeitada".

Para Germano Marques da Silva (2001) a dignidade natural resulta da autonomia, racionalidade ou espiritualidade que caracteriza o homem (interpretação fisiológica) e do fato de o homem ser criado à imagem de Deus (interpretação teleológica). Lenoir e Mathieu (1998, p. 100-102) enumeram os princípios que se coligam com o conceito de dignidade: "o da não-discriminação (nomeadamente em função da raça); o direito à vida; proibição de tratamentos cruéis, desumanos ou degradantes; o respeito pela vida privada e familiar; o direito à saúde; a liberdade de investigação (conciliada com o respeito da pessoa humana)".

No conceito de dignidade estão englobados os conceitos de direitos fundamentais e de direitos humanos. Embora sejam conceitos recorrentes usados como sinónimos ${ }^{2}$, deve-se fazer uma separação dos seus sentidos.

$\mathrm{Na}$ ótica de Sarlet (2001), os direitos fundamentais são "direitos do ser humano reconhecidos e positivados na esfera do direito constitucional positivo de determinado Estado" (p. 33), enquanto que direitos humanos são "posições jurídicas que se reconhecem ao ser humano como tal, independentemente de sua vinculação com determinada ordem constitucional, e que, portanto, aspiram à validade universal, para todos os povos e tempos, de tal sorte que revelam um inequívoco caráter supranacional (internacional)” (p. 33).

2 A expressão "direitos fundamentais" não é consensual na doutrina, porque emprega outras expressões para fazer referência à mesma categoria de direitos, tais como "direitos humanos", "direitos do homem", "direitos públicos subjetivos". 
A expressão direitos fundamentais não é consensual nas normas, que, para fazer referência à mesma categoria de direitos, emprega outras expressões.

Na perspectiva do constitucionalista Gomes Canotilho (2011, p. 1091) "os direitos do homem são direitos válidos para todos os povos e em todos os tempos (dimensão jusnaturalista-universalista); direitos fundamentais são os direitos do homem jurídico-institucionalmente garantidos e limitados espácio-temporalmente”.

Ora, quando se fala de direitos humanos, refere-se a direitos com projeção internacional, ao passo que os direitos fundamentais se referem a direitos salvaguardados pela Constituição de um determinado Estado. $\mathrm{O}$ índice de direitos humanos é, por norma, mais extenso que o dos direitos fundamentais. A previsão numa Constituição confere uma maior probabilidade dos direitos serem respeitados a rigor.

Do mesmo modo que o direito tem o seu sustento na pessoa humana tendo em vista a boa vivência social, também a dignidade é "a base essencial e inseparável da existência de cada um como pessoa humana” (OLIVEIRA, 2013, p. 18).

\section{Da Ética À Dignidade da Pessoa Humana}

Há princípios consensuais entre a espécie humana, onde se insere a cidadania, solidariedade, justiça ou a dignidade da pessoa humana. Isto porque o ser humano não se fecha no individualismo, só se realiza no encontro com o outro. A sociedade entende que são princípios que devem ser postos em prática, mas só a ética é que surge como promotora do seu cumprimento. A ética regula a conduta humana sendo que o ser humano é um animal social e o único animal político. É também o único ser ético por ser livre e por não ser manifestamente condicionado pelos instintos como os outros animais.

Os direitos humanos são sustentados juridicamente por forma a estabelecer dignidade a cada ser humano, permitindo-lhe viver do ponto de vista social, político, jurídico ou moral, podendo ser eticamente entendidos como a garantia da dignidade da pessoa humana, 
permitindo desta forma organizar e/ou harmonizar os antagonismos interpessoais e assim harmonizar as relações comunitárias.

A Declaração Universal dos Direitos Humanos prova a importância da ética como o exercício pleno da cidadania. Mais do que a vertente teórica, há a necessidade de cada indivíduo interiorizar o conjunto de princípios que constitui a ética para que possa moldar os seus comportamentos e assim possibilitar a convivência social. A ética aparece precisamente porque cada ser humano não vive isolado, em que todos devem ter uma vida digna que passa pela liberdade de viver plenamente.

A ética ilustra a capacidade do ser humano em saber distinguir as boas das más atitudes e ter consciência daquilo que elas provocam no seio de uma sociedade ou simplesmente a um outro ser humano. A ética, por representar os princípios norteadores da sociedade, leva o ser humano a fazer uma introspeção no sentido de procurar uma valoração entre o bem e o mal no sentido de alcançar um equilíbrio. Esta estabilidade relaciona-se com a justiça social. A evolução da sociedade é diretamente proporcional à evolução da ética no resguardo da dignidade da pessoa humana.

\subsection{O PRINCÍPIO DA DIGNIDADE DA PESSOA HUMANA}

Os direitos fundamentais, enquanto direitos humanos patentes nas ordens jurídicas dos Estados ou os direitos humanos que advêm de declarações ou convenções internacionais estão inseridos naquilo que é o conceito de dignidade da pessoa humana.

A dignidade da pessoa humana relaciona-se, então, intimamente com os direitos fundamentais que só são realizados ou devidamente protegidos em regimes democráticos. No entanto, os direitos fundamentais podem ser limitados ou mesmo abolidos, quando, em situações extremas, colidem com outros direitos fundamentais.

Nesta linha, não se pode designar a dignidade da pessoa humana como um direito fundamental, já que a dignidade é algo impossível de se perder e sequer de ser limitada, como já visto. É antes "um princípio jurídico que poderá ser utilizado na concretização e na delimitação do 
conteúdo de direitos fundamentais constitucionalmente consagrados ou na revelação de direitos fundamentais não escrito" (OLIVEIRA, 2013, p. 11).

Em pleno século XXI, a dignidade da pessoa humana é muito insuficiente em algumas sociedades. Em Portugal é um princípio constitucional ${ }^{3}$ que se caracteriza por ser o princípio fundante da comunidade jurídico-política, articulando-se com todos os outros princípios consagrados na Constituição da República Portuguesa e com os direitos fundamentais lá expressos. É deste princípio que advém todos os outros princípios e normas jurídicas que orientam ou regulam a vivência na nossa sociedade.

Numa análise ao princípio da dignidade da pessoa humana positivado na Constituição da República Portuguesa, o constitucionalista Jorge Miranda (2008, p. 10) determina as diretrizes que resumem a dignidade individual do ser humano:

1) A dignidade da pessoa humana reporta-se a todas e a cada uma das pessoas e é a dignidade da pessoa individual e concreta;

2) Cada indivíduo vive em relação comunitária, mas a dignidade que possui é dela mesma, e não da situação em si;

3) O primado da pessoa é o do ser, não o do ter; a liberdade prevalece sobre a propriedade;

4) Só a dignidade justifica a procura de qualidade de vida;

5) A proteção da dignidade das pessoas está para além da cidadania portuguesa e postula uma visão universalista da atribuição dos direitos;

6) A dignidade da pessoa pressupõe a autonomia vital da pessoa, a sua autodeterminação relativamente ao Estado, às demais entidades públicas e às outras pessoas.

Em diversos acórdãos dos tribunais portugueses se verifica constantemente a referência à dignidade humana como valor "supremo", "estruturante", "basilar" ou "vetor axiológico estrutural" da República Portuguesa.

3 Artigo $1^{\circ}$ da Constituição da República Portuguesa. 
A dignidade na Constituição da República Portuguesa constitui um princípio autónomo e vinculativo que, com um foco mais para um conteúdo negativo (o que não deve ser feito), pode-se afirmar que é um princípio consensual, estando em conformidade com que este princípio determina ${ }^{4}$. A dignidade humana, como é vista hoje, assenta fundamentalmente numa dimensão negativa já que é a situação indigna que promove o reconhecimento comum da necessidade de respeito. Assiste-se a violação deste princípio quando se determina comportamentos "visam a coisificação de pessoas concretas e situadas no mundo" (OLIVEIRA, 2013, p. 12), isto é, quando a pessoa deixa de ser tratada como tal, é como que instrumentalizada de forma degradante.

A autonomia é uma ideia bem evidente no princípio da dignidade da pessoa humana, pois este princípio está ligado à liberdade e à vontade da pessoa. Neste sentido, o princípio é posto em causa sempre que há interferência na vida privada sem consentimento ou quando alguém é impedido de fazer escolhas (OLIVEIRA, 2013). Todavia, casos existem em que o consentimento não invalida a dignidade da pessoa humana, como é o caso de um contrato de escravatura. Isto, porque há certos direitos que são inatos, sendo a dignidade da pessoa humana "o vetor de valoração de todos os direitos fundamentais" (OLIVEIRA, 2013, p. 14) . Como os direitos humanos fazem parte daquilo que é a dignidade da pessoa humana, sempre que esses direitos não são reconhecidos há violação do princípio da dignidade da pessoa humana. Opostamente, e sabendo que a dignidade humana se refere ao ordenamento jurídico como um todo, quando há violação deste princípio há, por norma, também uma violação de direitos fundamentais.

Posto isso, entende-se que o princípio da dignidade da pessoa humana, para produzir efeitos jurídicos, não tem forçosamente de estar consagrado na Constituição, pelo seu caráter fundamental. No entanto, a Constituição da República Portuguesa faz referência a este princípio logo no artigo $1 .^{\circ}$, sendo, como já visto, o valor supremo da ordem jurídi$\mathrm{ca}$, sendo que este princípio age como "critério interpretativo do inteiro teor do ordenamento constitucional” (FARIAS, 1996, p. 54).

4 Princípio que determina a condição humana como única e sem paralelo. 


\subsection{DA ÉTICA E DA MORAL}

O vocábulo ética tem a sua gênese no grego êthos, que diz respeito ao carácter ou ao modo de ser de uma pessoa, adquirida com o tempo um sentido peculiar (SILVA, 2001, p. 13). O homem não é ético por natureza; é uma aprendizagem de algo que se vai adquirindo (ou não), onde se está perante uma ciência de prática onde "fazer é aprender".

De acordo com Stork e Echevarría (1996) a ética é "algo intrínseco à pessoa, à sua educação e ao seu desenvolvimento natural. É o critério de uso da liberdade" (p. 111), sendo que "o homem, ou é ético, ou não é homem” (p. 112). Corresponde a um conjunto de valores morais e princípios que norteiam a conduta humana na sociedade. Na perspectiva da Filosofia, aprende-se com o estudo dos valores e dos princípios morais de uma determinada sociedade e dos seus grupos, ou seja, o estudo da conduta humana.

Clemente (2016) expõe que a ética tem como fim incentivar a promover a felicidade humana, por intermédio de uma realização do bem próprio de cada homem e da sua contribuição para o bem social; e destaca ainda que "a ética é imortal e o homem infinito" (p. 15), apontando que a ética ultrapassa o carácter efémero do homem.

A ética existe e faz parte de toda uma sociedade, mas não se pode considerar como sendo a causa da tomada de decisão dos atos de cada cidadão, uma vez que apenas "pretende fornecer uma orientação para a vida ativa dos seres humanos" (SANTOS, 2012, p. 32), como que um guia de orientação num mapa terrestre. $O$ perigo, figurado na violência e na arbitrariedade comportamental, é um fator constante na vida do ser humano e nas relações interpessoais e, muitas das vezes, a paz, a harmonia e a ordem só é alcançável através da proteção do outro, ou seja, através da lei (STORK; ECHEVARRÍA, 1996), que no caminho de Clemente (2016), esta lei opõe-se à força bruta, à qual Stork e Echevarria (1996) associam à violência enquanto uma "força sem lei, um poder sem medida que destrói a forma das coisas e impede a sua plenitude" (p. 323).

Apesar de muitas das vezes se confundir a ética com a lei positi- 
vada, por diversas ocasióes é associada, intimamente, ao sentimento de justiça social. Normalmente, pode-se considerar os comportamentos éticos como bons. Entretanto, por sua vez, pode-se atribuir à bondade um elevado ônus de subjetividade, cujo dilema está na capacidade de saber escolher entre o "bem" e o "bem" (ou entre o "mal" e o "mal"), tendo em conta o interesse da maioria (BUCCI, 2000). De entre uma multiplicidade de escolhas que podem afetar terceiros, a ética torna-se o fator indicativo para se saber o que é mais ou menos justo e o que é mais ou menos injusto; é uma fundamentação e problematização das questões emergentes das opções e ações humanas, ao qual lhe é atribuído um carácter mais especulativo e teórico (SILVA, 2001).

A violação e o incumprimento dos princípios éticos de um determinado grupo ou sociedade sobre algum fato ou acontecimento, embora não tenham um valor vinculativo, normativo ou positivado na lei, podem conduzir a uma sentença ética, traduzida num juízo moral, positivo ou negativo.

A ética relaciona-se com as questões teóricas, o estudo da própria conduta humana; enquanto a moral se prende com as questóes práticas e coloca a própria ética em ação. Ao abordar o conceito de ética torna-se também fundamental estudar a ideia da moral.

A moral relaciona-se com o engenho de se viver bem, enquanto ser humano. Acomoda um conjunto de conhecimentos teóricos (éticos), de técnicas, experiências e destrezas necessárias para que o ser humano possa desempenhar, com desenvoltura, uma determinada atividade. Segundo Germano Marques da Silva (2001), assenta em valores e convenções estabelecidas dentro de cada cultura ou sociedade a partir da consciência individual, que distingue o bem do mal, que trespassa através dos tempos e das culturas. Valores universais como a honestidade, a bondade e a virtude servem então de alavancagem para a conduta humana. A moral faz parte integrante da constituição do homem, pois todo o ser humano possui consciência moral que o faz distinguir entre o bem e o mal, cabendo-lhe usar do livre arbítrio para agir de acordo com a sua liberdade, confrontando a sua ação com a norma que a rege. Em sentido lato, corresponde ao conjunto de normas e valores que são seguidos e praticados pelo ser humano, classificáveis, entre outros, de habituais, preconceituosos, supersticiosos, cruéis e irracionais. Num 
sentido mais estrito, prende-se, essencialmente, com a aplicação de normas e valores éticos, positivos ou certos.

Vários filósofos antigos distinguem o conceito de moral. Para Kant a moral corresponde a um conjunto de normas ditadas pela razão, as quais seriam as mesmas para todos os homens, em todas as épocas e lugares (KANT, 1785). Essas ideias são contrapostas por Hegel ao argumentar que a "moralidade kantiana" é demasiado abstrata, vazia, inflexível e incapaz de motivar o ser humano, pelo que alvitra falar sobre etnicidade, como sendo um conjunto de crenças, valores e ideais que os homens de certa época e certo lugar carregam consigo, porque foram formados neles desde a infância e, porque por meio deles se entendem e convivem uns com os outros, formando sua identidade individual e coletiva (KANT, 1785).

Conclui-se assim, a moral e a ética são conceitos que se completam. A moral desenvolve-se pela sociedade ${ }^{5}$ ou o grupo que o indivíduo está inserido acabando assim por ser um controle social através de valores, enquanto a ética é intrínseca ao homem e está presente no seu caráter e nos seus atos.

\subsection{UMA ATUAÇÃo POlicial ORIENTAda PElas QUESTÕes ÉTICAS E MORAIS}

A evolução natural da paz numa sociedade está intimamente ligada a um correto desenvolvimento do papel da polícia (STORK; ECHEVARRÍA, 1996), que não se pode desprender das implicações éticas das atividades de segurança pública pois, na direção de Clemente (2016, p. 10) "se não há Estado sem polícia, não há igualmente, polícia sem ética: a ética policial que se exprimem comumente num código deontológico, o qual enforma os padrões de atuação do pessoal policial e se projeta na aplicação das medidas legais de polícia, como adiante se esclarecerá.

Por essa razão, a atividade da polícia deve orientar-se segundo princípios, valores e normas de natureza ética, com o desígnio de

5 Segundo Clemente (2016, p. 20) "conquanto haja uma moral pública, não existe uma moral privada (ou individual), entendida como uma moral sem a necessidade de aceitação ou de reprovação da comunidade, cujos conteúdos e práticas estejam ao nível de cada pessoa." 
moralizar as suas intervenções e humanizar as relações interpessoais. Refere-se à ética profissional, ou seja, os "problemas práticos de ordem socioprofissional com que se deparam os membros de uma profissão" (SILVA, 2001, p. 17), das responsabilidades e expetativas da própria profissão. Segundo Silva (2001), a ética profissional é "caraterizada pelo diálogo pluridisciplinar, permitindo o alargamento do problema identificado ao introduzir uma perspectiva que não seja redutora dos saberes especializados (p. 17).

Intimamente relacionado com a ética profissional está a ética policial que, sendo um ramo da primeira, no contexto policial, define Silva (2001, p. 20) que:

os policias devem satisfazer às mesmas exigências que todos os demais, acrescentando-lhes as exigências que todos os demais, acrescentando-lhes as exigências ligadas às carateristicas da profissão, às suas funções è circunstâncias em que devem decidir e agir (...) [exigindo-se-lhes uma confiança na sua integridade, pois, ] é esta confiança que, em grande parte, mantém a ordem e a estabilidade social e é condição da legitimação sociológica da polícia.

Segundo Clemente (2016), a polícia é considerada a defensora da lei, em prol da ética. Para o autor, existe uma relação entre quatro conceitos designadamente a ética, a violência, a polícia e o homem, sendo que "a ética eleva; a violência rebaixa: a polícia protege... O homem progride!” (CLEMENTE, 2016, p. 17); todavia, defende que nem toda a violência é negativa, pois em determinadas circunstâncias justifica-se o uso regulado da força, visto que "só o uso da força legítima, ou melhor, da força policial, consegue parar o uso da força bruta, ou seja, da violência cega" (CLEMENTE, 2016, p. 18).

A atuação da polícia é direcionada para a prevenção de atos e condutas que tenham repercussões graves a nível social, concluindo-se, assim, que a polícia existe para prevenir o mal. Por sua vez, a polícia deve proporcionar o bem na horizontalidade social e, esta situação só se verifica se a polícia for eticamente irrepreensível, ou seja, tem de atuar da forma mais correta possível, sempre de acordo com os padrões éticos.

Pode-se dizer que a ação da polícia encorpa um conjunto de padrões éticos, claros e globalizados. Enquanto a ética orienta a polí- 
cia, os valores éticos regulam a própria ação policial (CLEMENTE, 2016) cuja base é uma orientação da conduta do policial, enquanto ser e enquanto profissional representativo do Estado.

Nesse sentido, pode-se afirmar que a ética é o pilar fundamental de uma sociedade democrática e de uma polícia reguladora e fiscalizadora de comportamentos e, daqui resulta a necessidade de se formarem Estados detentores de valores e de um bem-comum de excelência. A ética guia-nos no trilho, iluminando-o para o bem-comum repleto de valores, e, é dessa forma que é possível afirmar que se consegue assegurar os direitos, liberdades e garantias dos cidadãos, tal como a própria dignidade da pessoa humana.

\section{Da Legitimidade do Estado no Uso da Força}

Para Weber (2007, p. 57), o Estado representa uma relação de domínio, a qual só poderá existir "sob condição de que os homens dominados se submetam à autoridade continuamente reivindicada pelos dominadores" onde, implicitamente, os primeiros abdicam de certos direitos para o Estado ou outras autoridades do Estado, às quais lhe é reconhecida uma autoridade. Uma das premissas-chave do contrato social ou do contratualismo baseia-se em teorias ${ }^{6}$ que levam a uma renúncia ao recurso de violência por parte dos cidadãos como meio de resolver conflitos, depositando tal desidrato no Estado, ao qual é reconhecido a manutenção da ordem social.

O Estado configura-se, então, como um sistema social com o "monopólio ou a exclusividade da satisfação de necessidade coletivas" (OTERO, 1995), dispondo para tal de inúmeros recursos, dos quais se destaca o recurso à força coerciva. O Estado impõe-se como um regulador social, fazendo para isso uso de determinadas prerrogativas, sendo uma delas o recurso à violência.

A violência assume-se como um fenômeno inerente à natureza do ser humano, e é "racional até ao ponto de ser eficaz em alcançar a

6 Autores como Thomas Hobbes (1651), John Locke (1689) e Jean Jacques Rousseau (1762) são os mais famosos filósofos contratualistas. As teorias do contratualismos difundiram-se entre o século XVI e XVII como forma de explicar a origem legítima dos governos (J.RIBEIRO, 1999). 
sua finalidade" (ARENDT, 1985, p. 44). Historicamente, a violência sempre andou ao lado do poder, pois era uma forma de impor a autoridade, fosse a nível familiar, laboral ou mesmo escolar. Porém, Elias (1989) estabelece que a violência só é aceita, socialmente, em locais e circunstâncias particulares e por determinados agentes.

A violência legítima compõe uma particularidade da autoridade do Estado, que se arroga do seu monopólio (MATIAS, 1978) onde, supostamente mais ninguém se pode socorrer deste meio de modo legítimo, excetuando os casos tolerados pelo Estado (WEBER, 2007), que transfere poderes a entidades privadas para o uso legítimo da força, como e.g. a delegação de competências para empresas de segurança privada ou ainda quando estejam em causa de direitos próprios, podendo o cidadão comum usar do direito de resistência, da legítima defesa e da ação direta quando essas estão impossibilitadas de recorrer às autoridades públicas. Ainda que essa ação tenha que ser sujeita a uma análise e a uma avaliação posterior pelos tribunais, não deixa de ser uma exceção, uma "delegação de poder conferida pelo Estado, através da lei" (CLEMENTE, 2014, p. 150). Os exemplos anteriores não contrariam a ideia de que é o Estado que abarca a violência física legítima, pois o monopólio do uso da força tanto se pode exteriorizar no direito de exercê-la como na possibilidade de permitir exercê-la.

Num "Estado de Direito vigora o princípio da legítima defesa policial do cidadão ou heterotutela, pelo que a autodefesa simboliza a exceção; a força policial age em primeira linha" (CLEMENTE, 2014, p. 144). De acordo com Elias (1989) o exercício da força é um instrumento do Estado, sendo por isso este o detentor do monopólio da violência física legítima. $O$ Estado surge assim como uma estrutura central monopolizadora da violência complexa, que controla as tensões sociais existentes, e garante o equilíbrio social ${ }^{7}$. Silva (2001, p. 64) afirma que "devemos ter em atenção que em democracia o uso da força não consubstancia um direito das forças de segurança, mas sim um dever, quando se verifiquem certos pressupostos e sempre com o fim de interromper ou evitar violações dos direitos fundamentais".

7 Deve atender às garantias e liberdades constitucionalmente plasmadas e às medidas de polícia legalmente previstas, sendo que a atuação da polícia se consubstancia muitas das vezes em restrições e limitações. 
É da pertença do Estado democrático de direito “o monopólio de regulação do emprego da força, isto é, o monopólio estadual de definição das condições de emprego da força, a que corresponde também a posição dominante de emprego da força" (CLEMENTE, 2014, p. 149), muitas das vezes presente em ações policiais repressivas, em situações de desordem pública ou em situações de especial gravidade e atentatória da segurança de bens e de pessoas.

O Estado tem como fim promover a defesa dos direitos pessoais, culturais, sociais e econômicos dos cidadãos, utilizando a ação das forças de segurança e demais instituições e entidades englobantes no conceito de polícia e dotando-as de poderes para o conseguir (VALENTE, 2010). Ao concentrar no Estado o monopólio do uso legítimo dos meios de violência, a ordem jurídica expropria dos indivíduos o recurso à violência (MILITÃO, 2001).

A polícia, um dos instrumentos essenciais do Estado para garantir a ordem e segurança interna, deve garantir um equilíbrio entre dar cumprimento sobre o que se encontra legislado e salvaguardar os direitos, liberdades e garantias dos cidadãos (ALVES, 2016). O equilíbrio alcança-se apenas quando a atuação se rege por fundamentos éticos. Segundo Clemente (2016, p. 25), "a ética antecede a legalidade: a consciência ética deve comandar o agir policial, para que seja preservada a dignidade humana”. Assim, a polícia deve recorrer a fundamentos éticos a fim de lesar o menos possível os direitos consagrados. Com o objetivo de alcançar a este fim, Valente ${ }^{8}$ (2012, p. 106) defende que o Estado democrático de direito deverá manter "a inquebrável arquitetura dos pilares biogenéticos: a dignidade da pessoa humana e a vontade do povo como pilares essenciais à efetividade dos direitos e liberdades fundamentais do ser humano. Essa efetividade só é possível em liberdade e em segurança, sem que uma aniquile a outra, mas que uma seja a razão de ser da outra e que o princípio da liberdade se afirme kantianamente como o mais elevado valor da justiça”.

Atualmente, são diversos os casos mediatizados que acusam os profissionais das forças de segurança de cometer o erro do uso excessivo da força. Assim, é essencial que os policiais conheçam "o horizonte

8 No artigo "Desafios aos fundamentos do Estado de Direito Democrático", em Poder Político e a Segurança, de Eduardo Pereira Correia e Raquel dos Santos Duque. 
do uso da força legítimo e os seus limites" (ALVES, 2016, p. 9) com o objetivo de garantir no exercício de sua atividade o não cometimento de nenhuma ilegalidade. $\mathrm{O}$ uso excessivo da força, além dos problemas decorrentes da lei, encerra-se na levitação de quesitos morais e éticos por parte da sociedade. Conforme refere Clemente, "o sentido ético marca as boas práticas policiais” (CLEMENTE, 2016, p. 25), sendo que os erros cometidos na atividade policial comprometem gravemente a qualidade da ação policial (CRAWFORD, 2007). A diversa legislação tem como fim evitar a discricionariedade por parte dos policiais, constituindo um limite material à atividade deles (ALVES, 2016). A ação policial será ética sempre que respeitar os fundamentos que sustentam um Estado democrático e que são demonstrativos dos valores éticos da sociedade (SILVA, 2001).

\section{O Uso da Força em Ação Policial}

Em um Estado democrático de direito, os imperativos da Lei Fundamental disciplina e delimita a atuação das instituições e circunscreve os parâmetros jurídicos e o panorama de valores a atender. À polícia, enquanto aparelho representativo da força do Estado, compete sustentar a convivência da sociedade e a preservação da comunidade. Como afirma Clemente (2016, p. 33), “a comunidade humana necessita de uma autoridade que a governe" . Apesar do Estado possuir (ainda $)^{10}$ o monopólio do uso da força, e as forças de segurança serem a face visível dessa legitimidade concedida pelos cidadãos, "deve-se ter em atenção que em democracia o uso da força não consubstancia um direito das forças de segurança, mas sim um dever quando se verifiquem certos pressupostos e sempre com o fim de interromper ou evitar violações dos direitos fundamentais" (SILVA, 2001, p. 64).

A materialização da força usada pela polícia caracteriza-se por uma possibilidade da prática de "atos capazes de ameaçar ou causar

9 Tal como nas teorias do Contrato Social, desenvolvidas essencialmente por Thomas Hobbes, John Locke ou Rousseau (vide nota de rodapé 7).

10 Veja-se o recurso cada vez maior, mesmo por parte do Estado, a serviços de segurança privada - de acordo com João Afonso, na tese de doutoramento A privatização de funções de segurança pública interna: funções inalienáveis do Estado democrático de direito e novo paradigma de descentralização do exercício de poderes de polícia, orientada pelo Manuel Guedes Valente. 
danos físicos aos cidadãos (KLAHM; FRANK; LIEDERBACH, 2014), em virtude desse poder ocorrer apenas e só em determinadas situações específicas porque, facilmente se percebe, que nem toda a atividade desenvolvida pela polícia se caracteriza pelo uso da força.

Pode-se estabelecer, de modo geral, um conjunto situações em que o uso da força é adequado e proporcional de outros em que se torna inadequado e desproporcional, ao qual se designa de uso excessivo da força, ou seja, onde é empregado "mais força do que é necessário para consumar uma detenção ou lidar eficazmente com um cidadão" (GAINES, 2005, p. 61), derivado de um incumprimento ou má interpretação das diretrizes técnico-policiais. Na trilha de Toch \& Geller (1996), deve-se fazer uma correta análise da ação da aplicação da força para não se tornar desnecessária e/ou inadequada; cessá-la quando já não existir a necessidade efetiva da sua aplicação, que a torna desnecessária; empregá-la indevidamente de forma voluntária e intencional; ou inadvertidamente através de erro ou uso indevido em aplicá-la involuntariamente.

Dessa forma, enquanto representante da força do Estado, toda a atuação policial deve ter por base a observância das regras legais bem como de valores éticos, atuando de forma a evitar o uso da força. $\mathrm{O}$ uso indevido da força através do emprego de uma violência de forma injustificada ou desrespeitadora e violadora de princípios éticos colocará em causa toda a legitimidade da polícia e, consequentemente, do Estado.

Pode-se assim afirmar que a "ética guia a polícia" (CLEMENTE, 2016, p. 9) e, num Estado democrático de Direito, em toda a sua atuação, nomeadamente quando é necessário o uso da força, é fundamental que a atuação policial siga um padrão de atuação, que permita reforçar a legitimidade reconhecida pelos cidadãos ${ }^{11}$. Em uma sociedade cada vez mais mediatizada, onde cada cidadão é um repórter/ jornalista em potência e onde a atividade policial se encontra sujeita a um elevado escrutínio público, qualquer atuação policial que possa ser encarada como abusiva, é amplamente partilhada em segundos. Apesar do escrutínio incidir sobre toda a atuação policial, os pontos de

11 A violência/uso da força não é um fim em si mesmo, mas sim um ato material que visa executar um ato jurídico. 
maior interesse são aqueles onde possam estar presentes erros, falhas ou exageros policiais. São esses últimos que facilmente se transformam em notícia e são comentados por uma panóplia de atores.

\subsection{Limites À AÇÃo POLICIAL NA UTILIZAÇÃo DA FORÇA NO QUADRO NORMATIVO PORTUGUÊS}

Toda a atuação policial, nas mais diversas vertentes operativas e administrativas, deve pautar-se pelo equilíbrio entre a admissibilidade legal e a utilização dos seus poderes de forma proporcional, adequada e prudente, já que o afastamento das regras legais poderá fazer com que os profissionais incorram em sanções de natureza diversa, designadamente criminal, disciplinar e civil.

Existem diversos preceitos constitucionais, normativos e legais que visam orientar a conduta do policial numa perspectiva ética, social e profissional, enquanto um imperativo de todas as suas atuações, tais como, o Código Deontológico do serviço Policial ${ }^{12}$, a Carta Ética da Administração Pública ${ }^{13}$, o Código de Conduta para os funcionários responsáveis pela aplicação da lei ${ }^{14}$, o Regulamento Disciplinar da Polícia de Segurança Pública ${ }^{15}$ e a própria Lei Orgânica ${ }^{16}$.

De acordo com o artigo $266 .^{\circ}$ da Constituição da República Portuguesa "a Administração Pública visa a prossecução do interesse público, no respeito pelos direitos e interesses legalmente protegidos dos cidadãos" e "os órgãos e agentes administrativos estão subordinados à Constituição e à lei e devem atuar, no exercício das suas funções, com respeito pelos princípios da igualdade, da proporcionalidade, da justiça, da imparcialidade e da boa-fé". Além destes princípios, dedica um artigo à Polícia (artigo 272. ${ }^{\circ}$ ), estipulando que "a polícia tem por funções defender a legalidade democrática e garantir a segurança interna e os direitos dos cidadãos"(.$\left.^{\circ} 1\right)$, que "as medidas de polícia são as

12 Resolução do Conselho de Ministros n. ${ }^{\circ}$ 37/2002, de 07 de fevereiro de 2002.

13 Documento de referência com os princípios e as linhas de orientação em matéria de ética e conduta profissional dos funcionários da Administração Pública.

14 Resolução n. 3 34/169, adotado pela Assembleia Geral das Nações Unidas, em 17 de dezembro de 1079.

15 Lei n. ${ }^{\circ} 7 / 90$, de 20 de fevereiro.

16 Lei n. ${ }^{\circ} 53 / 2007$, de 31 de agosto. 
previstas na lei, não devendo ser utilizadas para além do estritamente necessário" (n. ${ }^{\circ}$ 2) e que "a prevenção dos crimes, incluindo a dos crimes contra a segurança do Estado, só pode fazer-se com observância das regras gerais sobre polícia e com respeito pelos direitos, liberdades e garantias dos cidadãos" (n. ${ }^{\circ}$ ). Por sua vez, o artigo $12 .^{\circ}$ da Lei Orgânica da Polícia de Segurança Pública estipula que "no âmbito das suas atribuições, a Polícia de Segurança Pública utiliza as medidas de polícia legalmente previstas e nas condições e termos da Constituição e da lei de segurança interna, não podendo impor restrições ou fazer uso dos meios de coerção para além do estritamente necessário”.

A prestação de um serviço de qualidade numa força como a Polícia de Segurança Pública é fundamental para que haja disciplina, daí que seja de enorme importância a existência de um regulamento disciplinar que se aplique ao pessoal com funções policiais dos seus quadros, independentemente da natureza do respetivo vínculo ${ }^{17}$. Estabelece o artigo 2. ${ }^{\circ}$ do Regulamento Disciplinar da Polícia de Segurança Pública que "a disciplina na Polícia de Segurança Pública - PSP consiste na exata observância das leis gerais do País, das regras especialmente aplicáveis aos elementos da PSP e das determinações que de umas e outras legalmente derivem".

Assim, enquanto uma instituição credível e imprescindível à manutenção de uma saudável democracia, a Polícia de Segurança Pública não pode manter no seu efetivo policiais que não cumpram o seu dever e, em casos de uso "de poderes de autoridade não conferidos por lei ou abusar dos poderes inerentes às suas funções, excedendo os limites do estritamente necessário, quando seja indispensável o uso de meios de coerção ou de quaisquer outros suscetíveis de ofenderem os direitos do cidadão" o Regulamento Disciplinar da Polícia de Segurança Pública prevê a pena de aposentadoria compulsiva e demissão ${ }^{18}$.

No que diz respeito à utilização de meios coercivos, a Polícia de Segurança Pública, mais especificamente em 2004, difundiu pelo seu efetivo uma Norma de Execução Permanente, intitulada de "Li-

17 Art. $^{\circ} 1^{\circ}$ n. ${ }^{\circ} 1$ da Lei n. ${ }^{\circ} 7 / 90$ de 20 de fevereiro - Regulamento Disciplinar da Polícia de Segurança Pública.

18 Artigo n. $^{\circ} 47, n^{\circ} 1$ e nº 2 al. a) do Regulamento Disciplinar da Polícia de Segurança Pública. 
mites ao Uso de Meios Coercivos" ${ }^{19}$, que veio simplificar, uniformizar e disciplinar a aplicação de meios coativos em situações específicas da vida real. Essas normas passaram a fazer parte da formação de todos os policiais ${ }^{20}$, onde é notório o destaque quer ao respeito pela dignidade da pessoa humana, quer à transparência da atuação policial ${ }^{21}$.

Em um rácio de exceção, por vezes a polícia tem necessidade de recorrer à arma de fogo que, por ser o meio mais gravoso ao dispor dos policiais requer, por isso, cuidados especiais e acrescidos. O Decreto-Lei n. ${ }^{\circ}$ 457/99, de 5 de novembro, regula o Recurso a Arma de Fogo em Ação Policial, prevendo no artigo $2 .^{\circ}$ a necessidade da observância dos princípios da necessidade e da proporcionalidade. Assim, no seu artigo $2 .^{\circ},{ }^{\circ} 1$ estipula que "o recurso a arma de fogo só é permitido em caso de absoluta necessidade, como medida extrema, quando outros meios menos perigosos se mostrem ineficazes, e desde que proporcionado às circunstâncias". No n. ${ }^{\circ} 2$ do mesmo artigo acrescenta ainda que "em tal caso, o agente deve esforçar-se por reduzir ao mínimo as lesões e danos e respeitar e preservar a vida humana”. O Decreto-lei prevê o recurso a arma de fogo e recurso a arma de fogo contra pessoas, prevendo também a obrigatoriedade de identificação do elemento enquanto policial, uma voz ou disparo de advertência, e uma proibição (relativa) caso haja a probabilidade de que se venham causar danos a terceiros, bem como a obrigatoriedade de relato mediante um relatório próprio.

A Norma de Execução Permanente que foi mencionada, além de prever todas as situaçôes supracitadas, vai ainda mais longe e pre$\mathrm{ve}^{22}$, por exemplo, três tipos de recursos à arma de fogo (passivo, efetivo e efetivo contra pessoas ${ }^{23}$ ), bem como a observância de mais princí-

19 Documento e matéria de classificação "Reservada".

20 Tanto da formação inicial como da formação contínua - desde logo por ser matéria de avaliação no teste escrito que é prova integrante do Plano de Formação de Tiro.

21 Desde logo pela obrigatoriedade de prestação de cuidados médicos e da comunicação ao superior hierárquico. Sendo que, em alguns casos, como na utilização das armas de fogo por exemplo, a comunicação é feita também ao Ministério Público.

22 Elementos previstos de acordo com o plasmado no artigo 3. ${ }^{\circ}$, do Decreto-Lei n..$^{\circ}$ 457/99, de 05 de novembro.

23 Considera-se o recurso passivo o simples empunhamento da arma de fogo, com o objetivo de persuadir ou dissuadir um suspeito que detenha um certo comportamento plasmado na lei; o recurso efetivo consiste na execução de disparos contra animais ou como meio de alarme, nas circunstâncias previstas, ou como meio de advertência ou intimidação, em conformidade com o preceituado no n. ${ }^{\circ}$ 2, do art. ${ }^{\circ}{ }^{\circ}$., ambos do Decreto-Lei no 457/99, de 05 de novembro; o recurso efetivo contra pessoas 
pios $^{24}$. A qualidade de um serviço policial passa pela uniformização e disciplina dos seus policiais, adequando as situações específicas e reais a toda a sua formação, sempre sob o referencial do respeito pela dignidade da pessoa humana onde, em situações in extremis, a segurança pública só é capaz de ser provida pelo recurso a material bélico, que "jamais pode ser assegurada com o recurso desproporcionado à arma de fogo, ainda que haja o uso de munições menos letais, porque isso causa a erosão dos direitos pessoais e diminui a legitimidade da ação policial" (CLEMENTE, 2016, p. 34).

\subsection{Os eXórdios ético-deontológicos Na Polícia de Segurança Pública}

$\mathrm{Na}$ prática, os deontologistas são os protetores da ética e associam o dever à moral. A origem do termo deriva na palavra grega deon que significa "deve-se". Nessa guisa, os deveres são compreendidos como ações particulares que o homem deve praticar ou abster-se ou que são certas ou erradas. A ação do homem não é avaliada como certa ou errada pelas consequências do seu resultado, mas sim pela sua intenção, como e.g. a ação da prática de um atentado deve ser medida pela própria intenção da sua produção, independentemente dos danos do seu resultado, que até podem ser nulos.

$\mathrm{Na}$ deontologia são enumerados alguns deveres gerais que, embora a maioria sejam proibições, devem ser cumpridos e praticados por todos e entre todos, de entre os quais se destacam as ações de não matar, não mentir, não enganar; também existem deveres positivos ou obrigações, tal como ajudar os necessitados. Porém, na deontologia são ainda enumerados deveres que dependem das nossas relações pessoais, sociais e particulares, tal como o dever dos pais em sustentarem os filhos.

Esta preocupação ética e deontológica nas forças de segurança ganhou relevo em 1979 por iniciativa da Organização das Nações Unidas que em 17 de dezembro, através da Assembleia Geral, emitiu um "Código de Conduta dos Agentes Aplicadores da Lei" (resolução n. ${ }^{\circ}$

consiste na execução de disparo com o objetivo de atingir um ou mais suspeitos, nas situações previstas na norma de execução permanente.

24 Princípios da Legalidade, Necessidade, Adequação, Proibição de Excesso e Proporcionalidade (em sentido estrito). 
34/169), que veio a revelar-se essencial para a compreensão do emprego do uso da força policial no geral.

Nessa base, surge em 19 de setembro de 2001 o Código Europeu da Ética Policial, um conjunto de diretrizes emanadas pelo Comité de Ministros do Conselho da Europa, adotadas pela União Europeia, pelo Conselho da Europa e pelas Nações Unidas, que veio consagrar um conjunto de padróes ético-profissionais de conduta enquanto uma condição indispensável para um exercício credível e eficiente do serviço policial no Estado democrático de direito, recomendando um conjunto de melhores práticas policiais, como um garante de um exercício pleno de direitos, liberdade e garantias dos cidadãos.

As polícias portuguesas materializaram esta preocupação através de um Código Deontológico do Serviço Policial.

A Polícia de Segurança Pública, em especial, possui um conjunto de atribuições que permitem o condicionar e o restringir de direitos e liberdades individuais em favor do interesse público geral, onde se impõe uma ética profissional do serviço e fins concretos a que ele se destina. Nesse sentido, aprovado através da Resolução do Conselho de Ministros n. ${ }^{\circ}$ 37/2002, de 28 de fevereiro ${ }^{25}$, surge o Código Deontológico para o Serviço Policial, para a Polícia de Segurança Pública, cujo objetivo visa organizar, coordenar e definir um conjunto de deveres dos funcionários perante o cidadão. Percebe-se na sua criação que existiu uma preocupação clara com respeito pelos direitos fundamentais da pessoa humana, bem como o intuito de promover uma atuação correta $^{26}$ e imparcial por parte do policial.

No que diz respeito ao uso da força, destaca-se o artigo $8 .^{\circ}$ do Código Deontológico para o Serviço Policial, na medida em que refere os princípios da adequação, necessidade e proporcionalidade do

25 Publicado em Diário de República n. ${ }^{\circ}$ 50, I-B de 2002-02-28.

26 O código veio reforçar a "sujeição do uso de meios de coerção a critérios estritos de necessidade, adequação e proporcionalidade, com o respeito dos direitos, liberdades e garantias" e "a consagração de padróes ético-profissionais de conduta, comuns a todos os agentes das forças de segurança, é, reconhecidamente, condição indispensável para um exercício credível e eficiente do serviço policial, enquanto parte integrante do Estado democrático de direito" (Resolução do Conselho de Ministros n. ${ }^{\circ} 37 / 2002$, de 28 de fevereiro). 
uso da força. No mesmo sentido de toda a legislação, estipula que "os membros das forças de segurança usam os meios coercivos adequados à reposição da legalidade e da ordem, segurança e tranquilidade públicas só quando estes se mostrem indispensáveis, necessários e suficientes ao bom cumprimento das suas funções e estejam esgotados os meios de persuasão e de diálogo", numa avaliação do estritamente necessário, adequado e proporcional.

Nesse sentido ético e deontológico, uma atuação policial ética deve ser capaz anteceder a legalidade, constituindo-se como proporcional e adequada, tendo como máxima a preservação da dignidade humana, de modo a preservar a legitimidade da autoridade pública (CLEMENTE, 2016).

\subsection{Princípios NORTEAdores da ATIVIdAde POLICIAL}

Num passado recente, os principais objetivos prosseguidos pela atividade policial, embora não se revestissem de grande vulto o modo como atingidos, eram o bem geral e a segurança das pessoas. A polícia era caraterizada como sendo fortemente arbitrária, prevalecendo o despotismo.

Com o aparecimento dos Estados modernos, e com o legado das revoluções liberais, ergue-se o novo paradigma da ascensão do direito como um referencial ético, moral e político. O exercício das polícias não ficou à margem de todas essas transformações; porém, apesar de ser uma mudança extremamente positiva não se conseguiu erradicar, completamente, a discricionariedade na sua atuação, o que inevitavelmente, estimula a ocorrência de abusos (SILVA, 2001). A variedade e a multiplicidade dos exercícios das atividades individuais que pautam a intervenção das polícias tornam impossível que se preveja todas as circunstâncias e modos de atuação (VALENTE, 2012). Nessa premissa, o desempenho das funções das polícias regulada pelo respeito pela lei, pela jurisprudência e pela doutrina deve igualmente pautar-se pelos "princípios gerais do direito [e pelos] princípios gerais do ramo específico do direito a aplicar" (VALENTE, 2012, p. 169). 
São as orientações anteriormente indicadas que procuram contrariar, tanto quanto lhes é possível, a discricionariedade no exercício das forças de segurança, constituindo-se como um limite material à sua própria atividade. Não obstante de uma pluralidade de princípios norteadores da atividade policial, destacam-se três que se salientam no recurso ao uso da força policial.

Em primeiro, destaca-se o princípio da proibição do excesso ou da proporcionalidade em lato sensu. Situações existem em que a intervenção das forças de segurança se torna inevitável, mas cuja atividade terá que ser limitada para que as medidas tomadas nunca sejam desproporcionais aos fins que se pretendem alcançar, sendo que em circunstância alguma, os meios a empregar devem ser superiores ao mal a evitar, sendo que "o emprego da coação direta [,que compreende o emprego da força física pelo polícia ou mesmo, em casos extremos, através do recurso a meios coercivos auxiliares, permitidos por lei] recua perante outras modalidades coativas ablativas quando estas sejam adequadas e passíveis de adoção com sucesso" (CLEMENTE, 2014, p. 151).

Compete aos policiais avaliar minuciosamente a atuação e o meio a empregar para cada caso numa medida proporcional e de extrema necessidade, devendo existir um percurso na escalada da força que deve visar uma "crescente compreensão da esfera cívica, num esforço de menor lesão possível (...) [que inclui a] informação assertiva; comando verbal (ordem); coação física desarmada; algemagem; força física com bastão; arma menos letal; arma letal de fogo" (CLEMENTE, 2014, p. 151).

Esse princípio encontra dignidade constitucional nos artigos $18 .^{\circ}$, n. $^{\circ} 2,266 .^{\circ}$, n. $^{\circ} 2$ e $272 .^{\circ}$, n..$^{\circ} 2$ da Constituição da República Portuguesa. Este tem como corolários diretos, os princípios da adequação, da necessidade (ou da exigibilidade) e o da proporcionalidade em sentido restrito (ou da razoabilidade), conforme o artigo $272 .^{\circ}, \mathrm{n} .{ }^{\circ} 2 \mathrm{da}$ Constituição, não olvidando que é "um princípio enformador do princípio da legalidade como limite a quaisquer arbitrariedades do poder legislativo, do poder judicial e do poder executivo" (VALENTE, 2012, p. 176).

Dessa forma, este princípio consagrado num padrão ético-profissional de conduta comuns a todos os policiais como premissa 
de um exercício de um serviço policial credível e eficiente, encontra-se plasmado no artigo $8 .^{\circ}$ do Código Deontológico do Serviço Policial ${ }^{27}$, ao estabelecer no seu n. ${ }^{\circ} 2$ que "os membros das Forças de Segurança usam os meios coercivos adequados à reposição da legalidade e da ordem (...) só quando estes se mostrem indispensáveis, necessários e suficientes ao bom cumprimento das suas funções e estejam esgotados os meios de persuasão e de diálogo".

O segundo princípio que merece destaque é o princípio do respeito dos direitos e interesses legalmente protegidos dos cidadãos, forjado no $n .^{\circ} 1$ do artigo $272 .^{\circ}$ da Constituição da República Portuguesa, de onde se retira que os "direitos e interesses do cidadão são, por um lado, fundamento da atuação da polícia - um fim e si mesmo - e, por outro, um limite imanente da atividade administrativa em geral e, em especial, da atividade policial" (VALENTE, 2012, p. 188).

A esfera da defesa da legalidade democrática, da garantia da segurança interna e da própria garantia dos direitos dos cidadãos não pode ser alcançada a qualquer custo, pelo que os policiais não podem fazer recurso de qualquer meio que lhe permita alcançá-la.

Este princípio também encontra presença no Código Deontológico do Serviço Policial, mais precisamente no seu artigo $3 .^{\circ}$, sob a epígrafe "Respeito pelos direitos fundamentais da pessoa humana", estabelecendo no seu n. ${ }^{\circ} 1$ que " os membros das forças de segurança promovem, respeitam e protegem a dignidade humana, o direito à vida, à liberdade, à segurança e demais direitos fundamentais de toda a pessoa", onde o seu n. 2 reforça que, "em especial, têm o dever de, em qualquer circunstância, não infligir, instigar ou tolerar atos cruéis, desumanos ou degradantes".

Por último, traz-se à colação o princípio da concordância prática na ação da polícia que, tal como o anterior, visa fazer cumprir a proteção dos direitos fundamentais, cujo alcance deste objetivo se torna necessário que, muitas das vezes, se limite ou mesmo resigne outros direitos consagrados. Princípio indissociável da atuação policial,

27 Cf. Resolução do Conselho de Ministros n. ${ }^{\circ}$ 37/2002, de 7 de fevereiro de 2002.

A adoção pelos membros das Forças de Segurança de um Código Deontológico do Serviço Policial vem ao encontro da Resolução n. ${ }^{\circ} 690$ da Assembleia Parlamentar do Conselho da Europa, de 8 de maio de 1979, e da Resolução n. ${ }^{\circ}$ 34/169 da Assembleia Geral das Nações Unidas, de 17 de dezembro de 1979. 
traduz-se na salvaguarda de direitos individuais ou coletivos - v.g., direito à integridade física - e, em simultâneo, na compreensão de outros bens jurídicos, como a liberdade física. Nessa dicotomia de salvaguarda de direitos de uns e da restrição de direitos de outros, cuja fronteira separa o sacrifício desmesurado dos bens jurídicos afetados, "impõe a coordenação e combinação dos bens jurídicos em conflito de forma a evitar o sacrifício (total) de uns em relação aos outros (CANOTILHO apoud VALENTE, 2012, p. 219).

Esse princípio é ilustrado no artigo $4 .^{\circ}$ do Código Deontológico do Serviço Policial, cuja epígrafe:

Respeito pelos direitos fundamentais de pessoa detida" ao estabelecer a garantia dos demais direitos de um detido o qual já lhe foi suprimido um dos seus direitos fundamentais legalmente estabelecido - o direito à liberdade física -, ao plasmar no seu n. $^{\circ}$ 1. que "os membros das forças de segurança têm o especial dever de assegurar os respeitos pela vida, integridade física e psíquica, honra e dignidade das pessoas sob sua custódia ou ordem.

Certo é que o policial no decorrer de sua atividade, e raras as vezes, depara-se com uma escalada de violência repentina confrontando-se com situações de violência e/ou conflito, que colocam a vida e a integridade física de terceiros ou pessoal em causa. Porém, é no espaço temporal, que deve estar ciente e capaz de analisar a situação, e ter calma e prudência suficientes para que a sua atuação não resvale e desrespeite os demais princípios democráticos, e não inflija os direitos, liberdades e garantias dos cidadãos, que é cada vez mais conhecedor dos seus direitos.

\section{Conclusão}

A mais relevante conclusão que se chegou no presente estudo é a de que a atuação policial tem como fim maior prevenir ou afastar os efeitos da concretização de um perigo social, sempre com observância pelos demais limites normativos e princípios reguladores da sua atua- 
ção. As comunidades e o coletivo têm que acreditar na polícia, justa, reguladora e fiscalizadora de direitos externos (do coletivo societal) e internos (a própria intervenção policial).

Hodiernamente, as sociedades pautam-se por valores diferentes dos valores do passado, demonstrando uma enorme evolução das formas de agir e de pensar. Essa ênfase assume particular importância com a ascensão do fenômeno de violência nos Estados democráticos e a profunda alteração e crítica na vida social.

A violência legítima circunscreve-se ao domínio estatal, enquanto um "sistema social reconhecido pelos cidadãos para usar legitimamente a força quando tal se afigure necessário e as especialidades das circunstâncias o justificarem" (ALVES, 216, p. 65).

No entanto, o instrumento do uso da força, enquanto um instrumento dos órgãos coercitivos do Estado - a polícia -, deve ser utilizado segundo critérios definidos, onde se inclui a excepcionalidade, segundo critérios limitativos, em concordância com os limites plasmados na lei e outros diversos normativos gerais do direito e da função policial, sob a base do respeito da dignidade humana e os princípios éticos e morais que devem pautar uma ação policial.

Na pertinência da temática, na adversidade da natureza da missão policial perante situações que exigem a aplicação do poder conferido pelo Estado poderá preceder uma má atuação policial, passível de violar os direitos, liberdades e garantias dos cidadãos.

São esses dilemas éticos e morais que cabem às polícias mostrarem aos destinatários da própria ação policial que a conduta profissional antes de ser avaliada pelo cidadão comum, também o é por meio de um controle interno das próprias instituições em prol de uma melhoria do serviço policial. Destarte, não deve o policial coibir-se de usar a força sempre que necessário, porque o emprego da força de forma legítima, ética e consciente com os valores morais deve visar, principalmente, a proteção dos demais cidadãos. Uma ação policial só é legítima se for ética, pelo que se não o for, deixará igualmente de ser legítima; porquanto que "o que define o estatuto ético de uma determinada profissão é a responsabilidade que dela decorre, pois, quanto maior a sua 
importância, maior a responsabilidade que dela provém em face dos outros" (BITTAR, 2002, p. 363).

Bruno Miguel Fena Torres Correio

Centro de Investigação do Instituto Superior de

Ciências Policiais (ICPOL) e Segurança Interna

(ISCPSI) DE LISBOA

\section{Police Ethics: an Assumption inthe Use of Force In PORTUGaL}

\section{ABSTRACT}

Human rights and the Human person dignity are the main premise in police action. The legitimate force employed by the Police, in order to provide security to other citizens, is a symbol of sovereignty and the reason for the existence of a democratic State.

The action of security institutions may raise an Ethical doubt, since Ethics ends up being the guarantor and the legitimation of the action of the security forces, it becomes necessary to assess the limit of the sacrifice of Ethics in police activity, through the restriction of certain rights, freedoms and guarantees of citizens. Can violent police intervention protect human ethics? Police violence itself shouldn't be seen as a form of destructive violence; it must follow certain ethical parameters.

In this context, we intend to investigate the legitimacy of the use of force in police action, that is inseparable from the normative-legal perspective and from the other guiding principles of police activity, especially those referring to the use of police force.

KeYwOrds: Human rights. Human dignity. Ethics and morals. Police ethics. Police force.

\section{SOBRE LA ÉTICA POLICIAL: UNA PRESUNCIÓN EN el uso de la fuerza en Portugal}

\section{RESUMEN}

Los derechos humanos y la dignidad de la persona humana son la principal premisa en 
la acción policial. La fuerza legítima empleada por la policía, para brindar seguridad a los demás ciudadanos, es símbolo de soberanía y la razón de la existencia de un estado democrático.

La acción de las instituciones de seguridad puede suscitar dudas éticas, ya que la ética acaba siendo garante y la legitimación de la acción de las fuerzas de seguridad, se hace necesario evaluar el límite del sacrificio de la ética en la actividad policial, mediante la restricción de ciertos derechos, libertades y garantías de los ciudadanos. ¿Puede la intervención policial violenta proteger la ética humana? La violencia policial en sí misma no debe verse como una forma de violencia destructiva; sí, debe seguir ciertos parámetros éticos. En tal contexto, pretendemos investigar cuál es la legitimidad del uso de la fuerza en la actuación policial, inseparable de la perspectiva normativo-legal y de los demás principios rectores de la actividad policial, especialmente los referidos al uso de la fuerza policial.

Palabras clave: Derechos humanos. Dignidad humana. Ética y moral. Ética policial. Fuerza policial

\section{REFERÊNCIAS BIBLIOGRÁFICAS}

ALVES, D. Uso excessivo da força. Questões jurídicas, técnicopoliciais e sociais. Lisboa: ISCPSI, 216.

ARENDT, H. Da Violência. Brasília: Universidade de Brasília, 1985.

BARRETO, V. Ofetiche dos Direitos Humanos e outros temas. Porto Alegre: livraria do Advogado Editora Ltda., 2013.

BITTAR, E. C. Curso de ética jurídica: ética geral e profissional. São Paulo: Saraiva, 2002.

BUCCI, E. Sobre ética e imprensa. São Paulo: Companhia das Letras, 2000.

CANOTILHO, J. J. G. (.. E. C. Direito Constitucional e Teoria da Constituição. 9. ${ }^{a}$ Reimpressão da 7.a. ed. Coimbra: Livraria Almedina, 2011.

CLEMENTE, P. Polícia e segurança: breves notas. Lisboa:

Universidade Lusíada, 2014.

CLEMENTE, P. Ética Policial - Notas Breves. Lisboa: ISCPSI, 2016.

ELIAS, N. O processo civilizacional. Lisboa: Pub. Dom Quixote, v. I, 
1989.

FARIAS, E. P. Colisão de Direitos: a honra, a intimidade, a Vida privada e a imagem versus a liberdade de expressão e informação. Porto Alegre: SAFE, 1996.

GAINES, L. K. O Controlo da Polícia: a experiência americana. Conferência Internacional: Direitos Humanos e Comportamento Policial. Lisboa: Inspeção-Geral da Administração Interna. 2005. p. 53-80.

J.RIBEIRO, R. 3. Hobbes: o medo e a esperança. In: WEFFORT, F. C. Os Clássicos da Política. 12. ed. [S.1.]: Ática , v. 1, 1999. p. 53-77. KANT, I. Fundamentação da metafísica dos costumes. Lisboa: Edições 70 (2011), 1785.

KLAHM, C. F.; FRANK, J.; LIEDERBACH, J. Understanding police use of force Rethinking the link between conceptualization and measurement. Policing in international jornal of police strategies and managment, v. 37(3), p. 557-578, August 2014.

LENOIR, N.; MATHIEU, B. Les normes internationales de la bioéthique. Paris: PUF, 1998.

MATIAS, A. D. A Violência no Mundo Moderno. Lisboa: Livraria Bertrand, 1978.

MILITIÃO, M. A violência na sociedade actual. Controlo externo da actividade policial e dos serviços tutelados pelo MAI (pp. 295-302). Lisboa: Inspeção-Geral da Administração Interna, 2001. MIRANDA, J. Manual de Direito Constitucional, tomo IV. Coimbra: Coimbra Editora, 2008.

OLIVEIRA, F. Breves considerações a respeito do princípio da dignidade da pessoa humana. Porto: Faculdade de Direito. Universidade do Porto, 2013.

OTERO, P. O Poder de Substituição em Direito Administrativo: Enquadramento Dogmático-Constitucional. Lisboa: Lex, v. I e II, 1995.

Sarlet, I. W. Dignidade da Pessoa Humana e Direitos Fundamentais na Constituição Federal de 1988. Porto Alegre: Livraria do advogado, 
2001.

SANTOS, J. M. Introdução à Ética. Lisboa: Documenta, 2012.

SARLET, I. W. Dignidade da Pessoa Humana e Direitos

Fundamentais na Constituição Federal de 1988. Porto Alegre: Livraria do advogado, 2001.

SILVA, G. M. Ética Policial e Sociedade Democrática. Lisboa: ISCPSI, 2001.

SOUSA, R. C. D. O Direito Geral de Personalidade (Reimpressão). Coimbra: Coimbra Editora, 2011.

STORK, R.; ECHEVARRÍA, J. Fundamentos de Antropologia: Um Ideal de Excelência Humana. Brasil: Raimundo Lulio, 1996.

TOCH, H.; GELLER, W. Police Violence: Understanding and controlling police abuse of force. New Haven: Yale University Press, 1996. 292-328 p.

TOCH, H.; GELLER, W. Police Violence: Understanding and Controlling Police Abuse od Force. New Haven: Yale University Press, 1996. 292-328 p.

VALENTE, M. Teoria Geral do Direito Policial. 3. ed. Lisboa: Almedina, 2012.

Valente, M. Processo Penal. Tomo I, $3^{a}$ edição, Coimbra: Almedina, 2010.

WEBER, M. Ciência e Política - duas vocações. 14. ed. Berlim: Dunker \& Hunlot, 2007. 